\title{
Validating the Classical Failure Criteria for Applicability to the Notched Woven-Roving Composite Materials
}

\author{
Mohamed Mostafa Yousef Bassyouny Elshabasy \\ Department of Mechanical Engineering, Faculty of Engineering, Alexandria University, El-Horreya Avenue, El-Hadarra, \\ Alexandria 21544, Egypt \\ Correspondence should be addressed to Mohamed Mostafa Yousef Bassyouny Elshabasy; mohamed_elshabasy@alexu.edu.eg
}

Received 25 August 2013; Revised 9 February 2014; Accepted 11 February 2014; Published 24 March 2014

Academic Editor: Baozhong Sun

Copyright (C) 2014 Mohamed Mostafa Yousef Bassyouny Elshabasy. This is an open access article distributed under the Creative Commons Attribution License, which permits unrestricted use, distribution, and reproduction in any medium, provided the original work is properly cited.

\begin{abstract}
The classical failure criteria are phenomenological theories as they ignore the actual failure mechanism and do not concentrate on the microscopic events of failure. The main objective of the current investigation is to modify the classical failure theories to comprise the essential failure mechanism (interfacial shear failure) in the thin-layered woven-roving composite materials. An interfacial shear correction factor $\left(\mathrm{MH}_{6}\right)$ is introduced into the nondimensional shear terms in the studied classical failure criteria. Thus the validity of applying these theories to the investigated material will be augmented. The experimental part of the current study is conducted on thin-layered circular specimens. The specimens are fabricated from two plies of fiber E-glass woven-roving fabric reinforced with polyester. The fabrics are laid to have $\left[ \pm 45^{\circ}\right]$ or $\left[0^{\circ}, 90^{\circ}\right]$ fiber orientation. The specimens used are plain, where no macroscopic sources of stress concentration exist or having circular notches of five, seven, or nine mm radii. The specimens are subjected to low cycle completely reversed fatigue bending loading where the S-N and the R.D.-N curves are plotted for each group of specimens.
\end{abstract}

\section{Introduction}

The failure modes in woven-roving composite materials are more complex than those of other man-made materials or metals [1]. To improve the performance of these materials, the source of damage must be insightfully understood to prevent its subsequent evolution and the deterioration of fundamental mechanical properties. The adhesion integrity between fiber and matrix is the justification for superior composite materials properties over their constituent components as discussed by a lot of researchers [2-5]. Their investigations were focusing on the fiber/matrix interaction at micro level scale [2-5]. Moreover, different techniques have been proposed to measure the fiber/matrix adhesion levels [6-9]. Swan et al. [5] and Jayaraman et al. [10, 11] have proposed different analytical methodologies and experimental techniques to improve the interpretation of the interface region. Dasgupta and Sirkis [12] studied the effect of coating modulus and thickness on the stress distribution around an optical fiber subjected to axial loading. Carman and Case
[13] demonstrated that an optimal coating exists for the longitudinal shear problem. Carman et al. [14] analytically investigated the influence of finite size interphase coatings applied to the structural fiber on the stress distribution in continuous unidirectional composite subjected to transverse loading. They also proposed an optimization of fiber coating procedure to reduce the stress concentration at the fiber matrix interaction locations. At the macrolevel scale, Madhukar and Drazal [15-18] published a series of papers describing the considerable effect of the interphase/interface on macrolevel strength and stiffness properties.

In 1960s, most of the classical failure criteria were proposed prior to the above mentioned studies. In the current investigation, a bridge between the classical failure theories which is phenomenological in nature and the interfacial deficiencies as the main cause of failure on the insightful interpretation is built. An interfacial shear correction factor denoted $\mathrm{MH}_{6}$ is used to augment the shear stress in the nondimensional shear term in the classical criteria. The modified classical criteria can fairly estimate the relative 


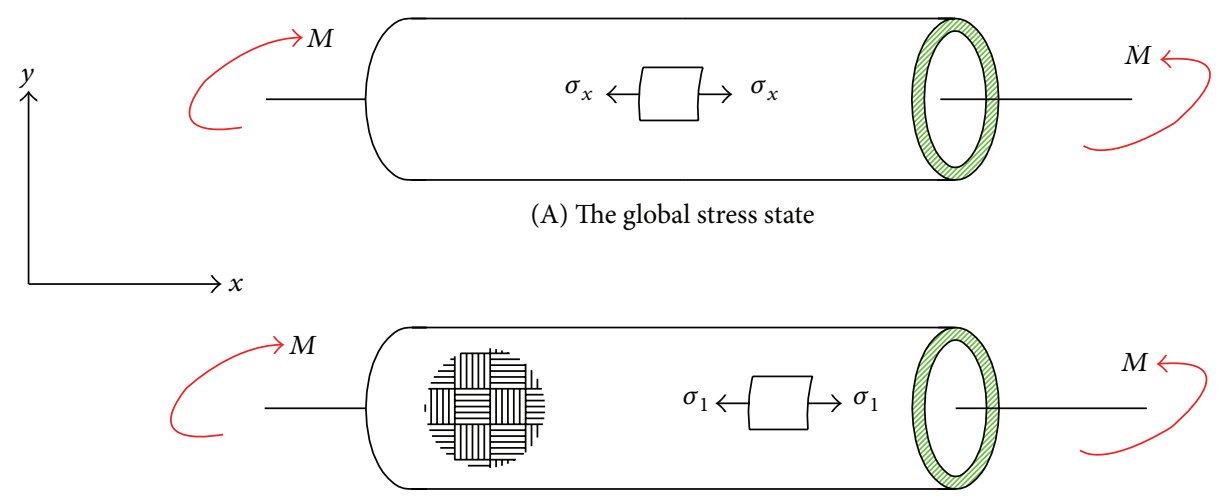

(B) $(0,90)$ FRP tubular specimen

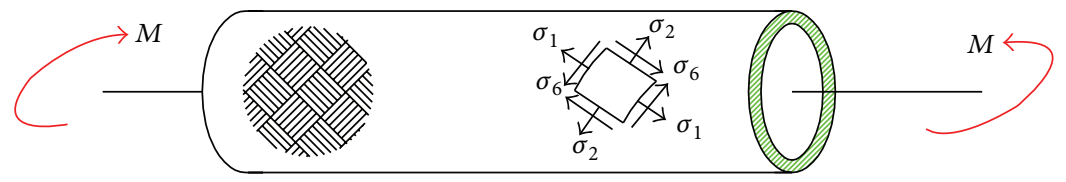

(C) ( \pm 45$)$ FRP tubular specimen

(a)

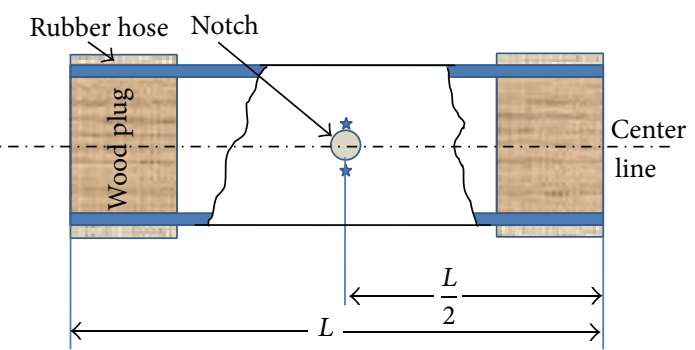

* Location of stress element

(b)

FIgURE 1: (a) Stress state of $\left[0^{\circ}, 90^{\circ}\right]_{2 s}$ and $\left[ \pm 45^{\circ}\right]_{2 s}$ specimens under pure bending loading. (b) Location of stress element of a notched specimen.

damage of the tested material under the assigned loading type.

The rest of the paper is organized as follows. Section 2 presents the analytical analysis. Section 3 provides the experimental work. The experimental data used in our previous investigation [1] are also used for the current study. The validation procedure of the studied classical criteria is explained in Section 4. Finally, the paper is concluded in Section 5.

\section{Analytical Analysis}

2.1. Stress Representation. As the specimens were subjected to completely reversed bending stress, the only existing stress component, $\sigma_{x}$, is the stress in the global $x$-axis (see (1)):

$$
\sigma_{x}=\frac{M \cdot Y}{I}
$$

where $M=M_{m}+M_{v}$, for completely reversed loading $M_{m}=$ 0.0 and $M_{v}=A \sin \omega t$.

Based on the global stress calculated above, the local stress components could be calculated based on fiber orientation as follows. For stress element of $\left[0^{\circ}, 90^{\circ}\right]_{2 s}$ specimens, $\sigma_{1}=\sigma_{x}$, $\sigma_{2}=\sigma_{6}=0$. For stress element of $\left[ \pm 45^{\circ}\right]_{2 s}$ specimens $\sigma_{1}=$ $\sigma_{2}=-\sigma_{6}=\sigma_{x} / 2$. Figure 1(a) shows these two stress states. Notice that the stress element is located at the midpoint of the middle length of the plain specimens as shown in Figure 1(a). For the notched specimen, the stress element was selected to be on the midline of the specimen length, above or below the notch where the moment loading value is uniform. These points are denoted with stars as shown in Figure 1(b). Notice that the distance between these points and the neutral axis is almost equal to the mean radius of the specimen cross section, such that the global stress at these points (denoted with stars in Figure $1(\mathrm{~b})$ ) is equal to $\sigma_{x}$ (see (1)).

2.2. Theories of Failure. The diversity of the woven-roving composite material application made the need for the simple failure criteria to account for the microscopic failure modes in the composite structures a demanding task. Most of the modern failure criteria of composite material are proposed to account for the complexity of failure mechanisms in the 
composite materials which does not heavily exist in the thinlayered specimens used in the current study. Besides, the fatigue process in thin-layered woven-roving fiber reinforced with ductile matrices is similar to that in metals in the sense that it consists of two stages: crack initiation followed by crack propagation [1]. For the previous reasons, the classical failure criteria listed in Table 1 are focused on and the modern criteria are out of the current scope.

The classical failure criteria are not based on the physical mechanisms that are blamed for failure on the microscopic level at the time these theories were introduced. These theories are also known as phenomenological theories. Some of the recent forms of these classical criteria include normal stress interaction terms " $\sigma_{1} \sigma_{2}$ " and stability condition factors $H_{12}$ which are used to account for the material anisotropy; see Table 1. Nevertheless, they did not reflect the dominant microscopic failure mechanism (interfacial shear failure) in the notched Woven-roving Fiber Reinforced Composite (WRFRC) thin-layered materials. Hence, an augmentation of the shear stress component is required to validate these criteria for applicability to the studied material.

As seen in Table 1, these criteria are based on the principal static stresses together with their corresponding static strength. In the present study, the principal fatigue stress components $\left(\sigma_{1}, \sigma_{2}\right.$, and $\left.\sigma_{6}\right)$ and the corresponding fatigue strengths $\left(F_{1}, F_{2}\right.$, and $\left.F_{6}\right)$ are used in the failure criteria [19]. The values of the fatigue strengths $F_{1}, F_{2}$, and $F_{6}$ are calculated from tests conducted on five-layer plates fabricated from the same constituent materials of the studied materials. The common observation in these theories is that the nondimensional shear stress component is not coupled with any of the other nondimensional local principal stresses.

These criteria could be further simplified based on the fiber orientation as shown in Table 2 . The simplified criteria for $\left[0^{\circ}, 90^{\circ}\right]_{2 s}$ specimens do not contain the nondimensional shear stress term as the local shear stress component is zero. When applying those theories to $\left[0^{\circ}, 90^{\circ}\right]_{2 s}$ and $\left[ \pm 45^{\circ}\right]_{2 s}$ specimens, we will consider the following.

(i) $F_{1}=F_{2}=$ the fatigue strength of plain $\left[0^{\circ}, 90^{\circ}\right]_{2 s}$ specimens subjected to completely reversed bending test. Consequently, Norris distortional energy [20], Hoffman [21], Tsai-Wu [22], Tsai-Hahn [23], Cowin [24], and Puppo [25] criteria will yield to the Tsai-Hill yield criterion [26] as shown in Table 2.

(ii) $F_{6}=$ the shear endurance strength of plain $\left[0^{\circ}, 90^{\circ}\right]_{2 s}$ specimens subjected to completely reversed torsion test.

Notice that the simplified failure criteria of the $\left[0^{\circ}, 90^{\circ}\right]_{2 s}$ fiber orientation yield to the same form $\left(\sigma_{1} / F_{1}\right)^{2}=1$ as shown in Table 2. The reason for this is the zero values of the local stress components $\sigma_{2}$ and $\sigma_{6}$ as discussed before.

\section{Experimental Work}

3.1. Testing Machine. A strain controlled testing machine designed by Abouelwafa et al., [27] Sharara [28], and Elshabasy [29] is used to conduct the current experiments.
Figure 2 shows the two views of the testing machine. The testing machine was designed to perform pure bending, pure twisting moment loadings, or combined loading, whether in phase or out of phase, with a constant frequency of $8.75 \mathrm{~Hz}$. The loading system of the machine is independent and is designed to produce the load in form of sine wave with variable stress ratio $(R)$ between the minimum and maximum applied stresses. The bending system gives a fourpoint configuration. Therefore, the specimen is acted upon by a constant bending moment over its entire length. The applied bending moment is measured via a load cell. This cell is fixed on one of the two grippers and it has four active strain gauges, forming a full Wheatstone bridge.

3.2. Specimens. The thin-layered cylinder specimens were made of two layers of woven-roving E glass fabric, with equal glass intensity in both fill and warp directions. The reinforcing resin is SIROPOL 8330 Polyester. The Resin was treated with the methyl ethyl ketone peroxide as a catalyst in a percentage of 2.0 to $2.5 \%$ by volume, and the cobalt naphthenate $(6 \%$ solution) is used as an accelerator in a percentage of $0.2 \%$ by volume [29-31]. Cross-linking and curing took place at the ambient conditions. The nominal dimensions of the tested specimen are shown in Figure 3. Chamis [32] showed that optimum load transfer between fiber and matrix occurs when the volume fraction varies between 0.55 and 0.65 . Therefore, the manufactured specimens with fiber volume fraction $\left(V_{f}\right)$ in the range of 0.5 to 0.64 by weight are accepted $[1,29]$. Figure 3 shows the layout of the specimen with the two wooden plugs at the specimen end and rubber sleeve to relief and distributes the contact stress between the specimen ends and the copper gripper. The only counted failed specimens are those having failure signs at the middle third of the specimen length to avoid the failure emanating from the gripped ends.

3.3. Test Results. Before conducting the fatigue tests, five flat specimens made from five plies of the same constituent materials of the tubular specimens were subjected to static bending loading. The bending strengths for both fill and warp directions are very close to the ASTM standards of glass composite [33]. The dimensions of the specimen and the test results are listed in Table 3 [1].

In order to avoid any misleading results, only the specimens that had their failure features within the gauge section (the middle third of the specimen length) were considered. More than 110 specimens for each orientation were used in running the fatigue tests. Each group of the same orientation is divided into two groups, plain and notched. The specimens are subjected to completely reversed bending fatigue loading with different amplitudes. Each experimental plotted point is obtained by considering the average of three to five specimens tested under the same conditions [33]. The test results are used in plotting the corresponding $S-N$ curve where they are fitted to the exponential form shown in

$$
S=\sigma_{\max }=a N^{b}
$$


TABLE 1: Classical failure criteria of the composite materials.

\begin{tabular}{lll}
\hline Number & Name and reference & Failure criterion \\
1 & Hill criterion (Hill) [35] & $\left(\frac{\sigma_{1}}{F_{1}}\right)^{2}-\left(\frac{1}{F_{1}^{2}}+\frac{1}{F_{2}^{2}}\right) \sigma_{1} \sigma_{2}+\left(\frac{\sigma_{2}}{F_{2}}\right)^{2}+\left(\frac{\sigma_{6}}{F_{6}}\right)^{2}=1$
\end{tabular}

$2 \quad$ Tsai-Hill yield criteria (Azzi and Tsai) [26]

$$
\left(\frac{\sigma_{1}}{F_{1}}\right)^{2}-\left(\frac{\sigma_{1} \sigma_{2}}{F_{1}^{2}}\right)+\left(\frac{\sigma_{2}}{F_{2}}\right)^{2}+\left(\frac{\sigma_{6}}{F_{6}}\right)^{2}=1
$$

3

Norris interaction (Norris and McKinnon) [36]

$$
\left(\frac{\sigma_{1}}{F_{1}}\right)^{2}+\left(\frac{\sigma_{2}}{F_{2}}\right)^{2}+\left(\frac{\sigma_{6}}{F_{6}}\right)^{2}=1
$$

4

Norris distortional energy (Norris) [20]

Hoffman theory (Hoffman) [21]

$$
\begin{gathered}
\left(\frac{\sigma_{1}}{F_{1}}\right)^{2}-\left(\frac{\sigma_{1} \sigma_{2}}{F_{1} F_{2}}\right)+\left(\frac{\sigma_{2}}{F_{2}}\right)^{2}+\left(\frac{\sigma_{6}}{F_{6}}\right)^{2}=1 \\
\left(\frac{\sigma_{1}}{F_{1}}\right)^{2}=1 ; \quad\left(\frac{\sigma_{2}}{F_{2}}\right)^{2}=1
\end{gathered}
$$

$$
\frac{\sigma_{1}^{2}-\sigma_{1} \sigma_{2}}{F_{1 t} F_{1 c}}+\frac{\sigma_{2}^{2}}{F_{2 t} F_{2 c}}+\left(\frac{F_{1 c}-F_{1 t}}{F_{1 c} F_{1 t}}\right) \sigma_{1}
$$

$$
+\left(\frac{F_{2 c}-F_{2 t}}{F_{2 c} F_{2 t}}\right) \sigma_{2}+\left(\frac{\sigma_{6}}{F_{6}}\right)^{2}=1
$$

$$
\left(\frac{1}{F_{1 t}}-\frac{1}{F_{1 c}}\right) \sigma_{1}+\left(\frac{1}{F_{2 t}}-\frac{1}{F_{2 c}}\right) \sigma_{2}+\frac{\sigma_{1}^{2}}{F_{1 t} F_{1 c}}+\frac{\sigma_{2}^{2}}{F_{2 t} F_{2 c}}
$$

The same criterion as Tsai Wu but the value of $H_{12}$ is

$$
H_{12}=-0.5 \sqrt{\frac{1}{F_{1 t} F_{1 c}} \cdot \frac{1}{F_{2 t} F_{2 c}}}
$$

The same criterion as Tsai-Wu but the value of $H_{12}$ is

8

Cowin [24]

$$
H_{12}=\sqrt{\frac{1}{F_{1 t} F_{1 c}}} \sqrt{\frac{1}{F_{2 t} F_{2 c}}}-\frac{1}{2 F_{6}^{2}}
$$

9

Puppo and Evensen [25]

$$
\left(\frac{\sigma_{1}}{F_{1}}\right)^{2}-\gamma\left(\frac{F_{1}}{F_{2}}\right) \frac{\sigma_{1} \sigma_{2}}{F_{1} F_{2}}+\gamma\left(\frac{\sigma_{2}}{F_{2}}\right)^{2}+\left(\frac{\sigma_{6}}{F_{6}}\right)^{2}=1, \quad \text { where } \gamma=\frac{3 F_{6}^{2}}{F_{1} F_{2}}
$$

$$
\left(\frac{\sigma_{1}}{F_{1}}\right)^{2}+\left(\frac{\sigma_{2}}{F_{2}}\right)^{2}+\left(\frac{\sigma_{6}}{F_{6}}\right)^{2}+2 F_{12} \sigma_{1} \sigma_{2}=1
$$

$$
F_{12}=\frac{1}{2}\left[\frac{4}{\sigma_{X}^{2}}-\frac{1}{F_{1}^{2}}-\frac{1}{F_{2}^{2}}-\frac{1}{F_{6}^{2}}\right]
$$


TABLE 2: Reduced forms of the classical failure criteria according to fiber orientation.

\begin{tabular}{llc}
\hline Theory & {$\left[0^{\circ}, 90^{\circ}\right]_{2 s}$} & {$\left[ \pm 45^{\circ}\right]$} \\
\hline Hill criterion [35] & $\left(\frac{\sigma_{1}}{F_{1}}\right)^{2}=1$ & $\left(\frac{\sigma_{6}}{F_{6}}\right)^{2}=1$
\end{tabular}

Tsai-Hill yield criterion [26], Norris distortional energy [20], Hoffman [21], Tsai and $\mathrm{Wu}[22]$, Tsai and Hahn [23], Cowin [24], and Puppo and Evensen [25] criteria

Norris interaction [36]
$\left(\frac{\sigma_{1}}{F_{1}}\right)^{2}$
$\left(\frac{\sigma_{1}}{F_{1}}\right)^{2}+\left(\frac{\sigma_{6}}{F_{6}}\right)^{2}=1$

(Nortis interaction $[36]$

$\left(\frac{\sigma_{1}}{F_{1}}\right)^{2}$

$2\left(\frac{\sigma_{1}}{F_{1}}\right)^{2}+\left(\frac{\sigma_{6}}{F_{6}}\right)^{2}=1$

Ashkenazi [37]

$\left(\frac{\sigma_{1}}{F_{1}}\right)^{2}$

$2\left(\frac{\sigma_{1}}{F_{1}}\right)^{2}+\left(\frac{\sigma_{6}}{F_{6}}\right)^{2}-\left(\frac{\sigma_{1}}{F_{6}}\right)^{2}+1=1$
or $2\left(\frac{\sigma_{1}}{F_{1}}\right)^{2}+\left(\frac{\sigma_{6}}{F_{6}}\right)^{2}-\left(\frac{\sigma_{1}}{F_{6}}\right)^{2}=0$
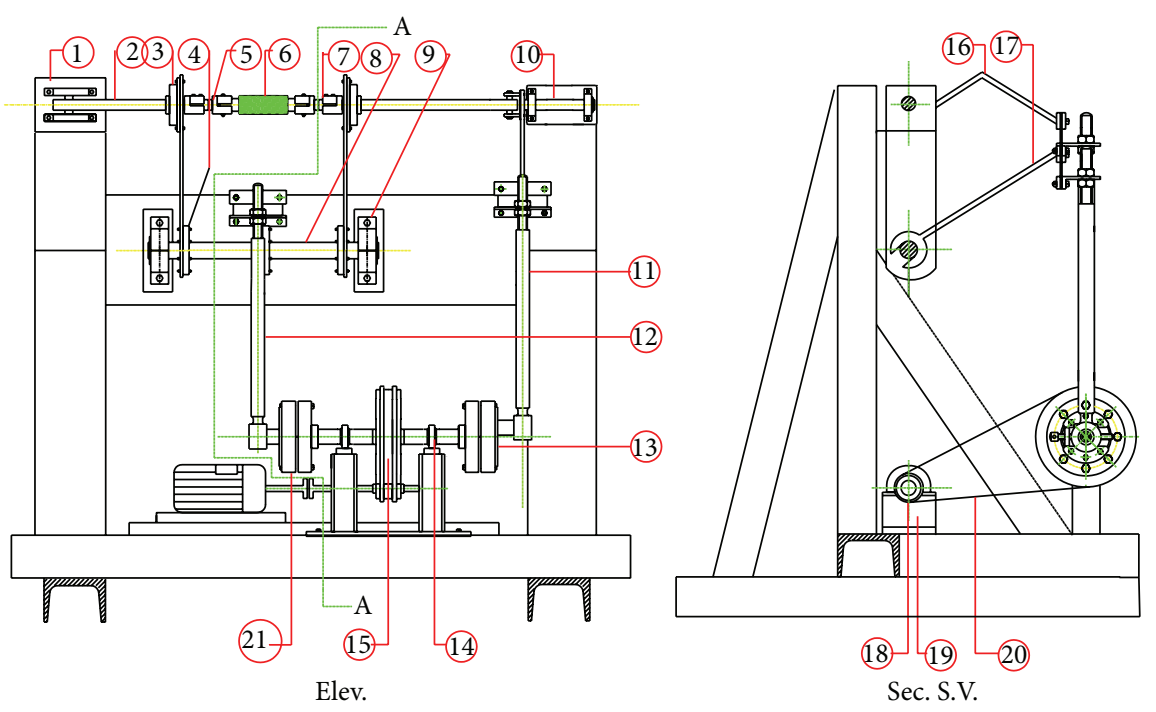

(1) Main frame

(12) Bending connecting rod

(2) Main shaft

(3) Self-aligning bearing

(13) Twisting moment coupling

(4) Bending loading arm

(14) Coupling shaft

(5) Bending transducer

(15) Driven pully

(6) Specimen

(16) Twisting moment loading arm

(7) Torque transducer

(17) Bending moment loading arm

(8) Intermediate shaft

(18) Driving shaft

(9) Deep groove ball bearing

(19) Motor table

(10) Guide shaft

(20) V belt

(11) Twisting moment arm

(21) Bending coupling

Figure 2: General layout of the testing machine [23]. 

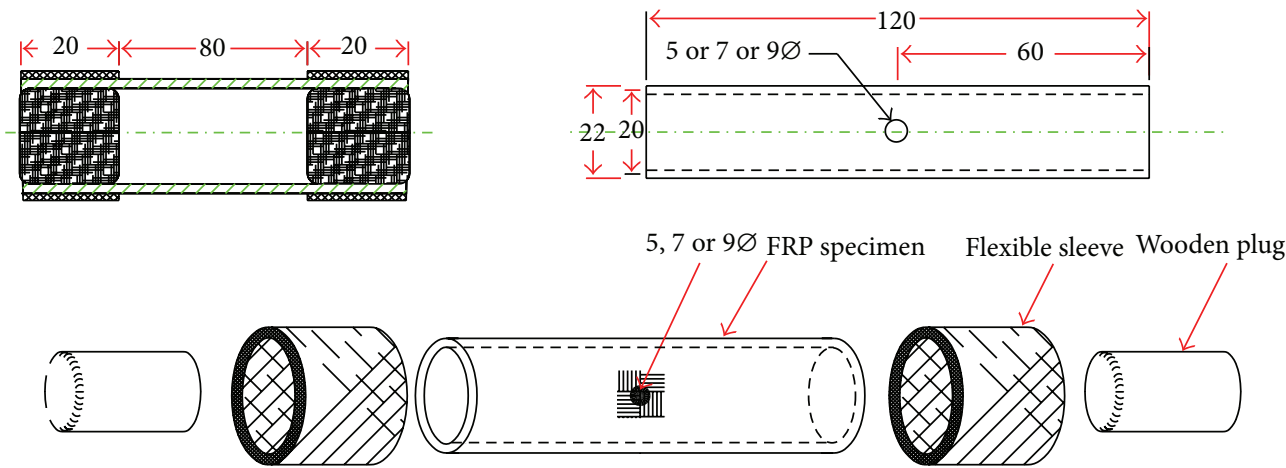

Specimen and gripping system

FIGURE 3: Specimen dimensions in $\mathrm{mm}$.

TABLE 3: Flexural strength for woven-roving glass fiber fabrics reinforced with polyester.

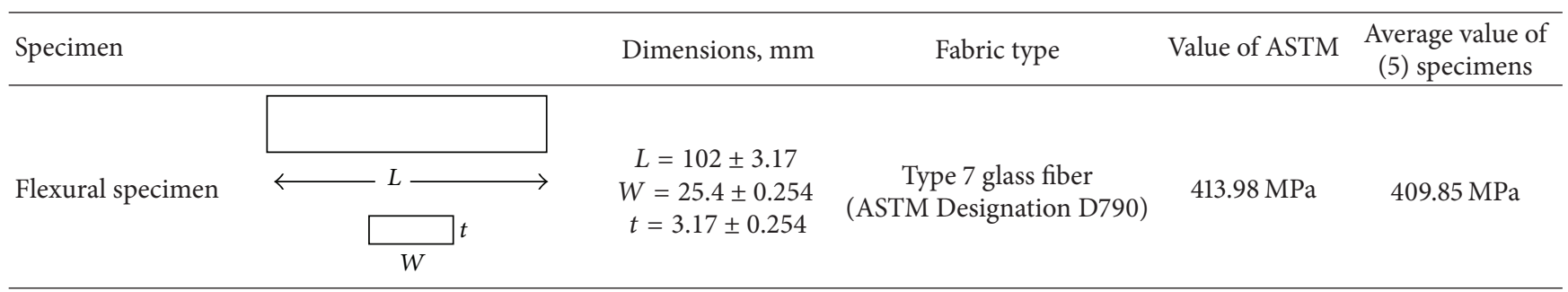

The test results of $\left[ \pm 45^{\circ}\right]_{2 s}$ specimens are used in plotting their corresponding $S-N$ curves, shown in Figure 4. Figure 5 shows the $S-N$ curves of $\left[0^{\circ}, 90^{\circ}\right]_{2 s}$ specimens. Figures 6,7 , 8 , and 9 are plotted for the sake of comparison between the $\left[ \pm 45^{\circ}\right]_{2 s}$ specimens and the corresponding ones having $\left(0^{\circ}\right.$, $90^{\circ}$ ) fiber orientations.

3.4. Failure Modes. The failure modes for the different studied specimens are clearly shown in the zoomed-in photos; see Figures 10 and 11.

For $\left[0^{\circ}, 90^{\circ}\right]_{2 s}$ plain specimen, the observed failure mode was a matrix-cracking mode normal to the loading axis and along the transverse fiber direction as shown in Figure 10. This may be attributed to brittleness of the matrix compared to the filling fiber fabrics. The matrix cracks, propagates, and stops at the interface as the fiber has a higher strength than the polyester matrix. In case of $\left[0^{\circ}, 90^{\circ}\right]_{2 s}$ specimens with holes, the observed failure mode is also matrix cracking and slight interfacial shear failure along the fiber tangent to the notch and parallel to the loading axis, as shown in Figure 12.

For $\left[ \pm 45^{\circ}\right]_{2 s}$ plain specimens, the observed failure mode is a combined mode of slight interfacial shear associated with slight matrix cracking; see Figure 11. For the $\left[ \pm 45^{\circ}\right]_{2 s}$ specimens with notch, a clear white zone extended along the uncut fiber tangent to the notch edges is shown in Figure 13. Although the visual inspection on the microscopic level was missing, the white damaged zone around the notch was visually inspected carefully. The debond between the fiber filaments and matrix was clear. The justification for this is that the load is mainly transferred by the interfacial region

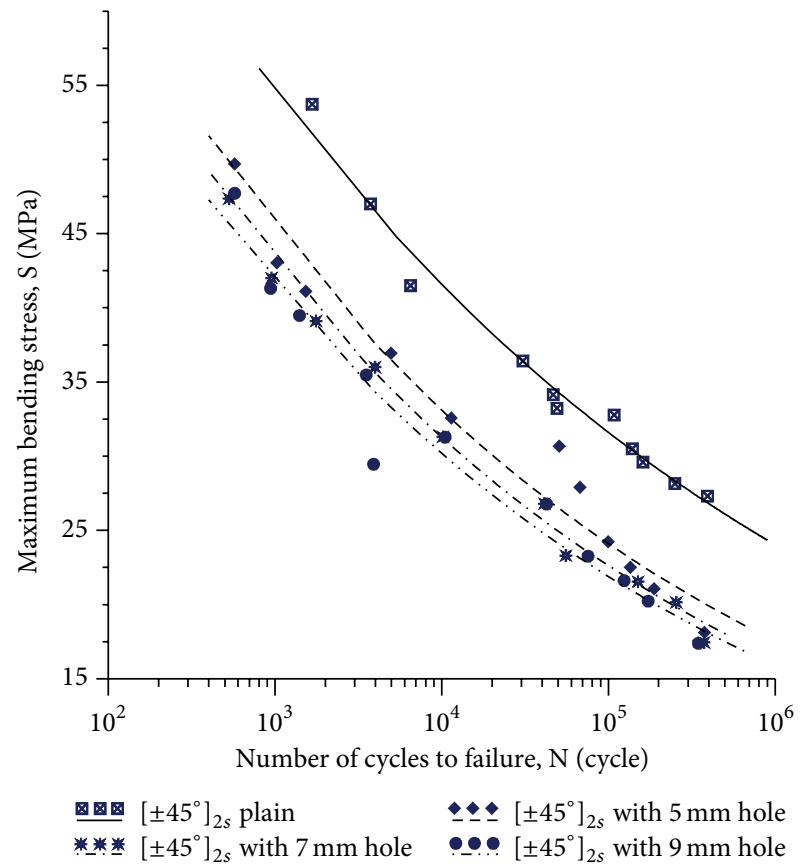

Figure 4: $S-N$ curves of $\left[ \pm 45^{\circ}\right]_{2 s}$ plain specimens and notched specimens holes of 5,7 , and $9 \mathrm{~mm}$ diameter holes.

between the fiber and matrix and the existence of shear stress component $\sigma_{6}[1,15-18]$. Another attestation for our interpretation is the $\mathrm{X}$-radiograph taking a graphite-epoxy 


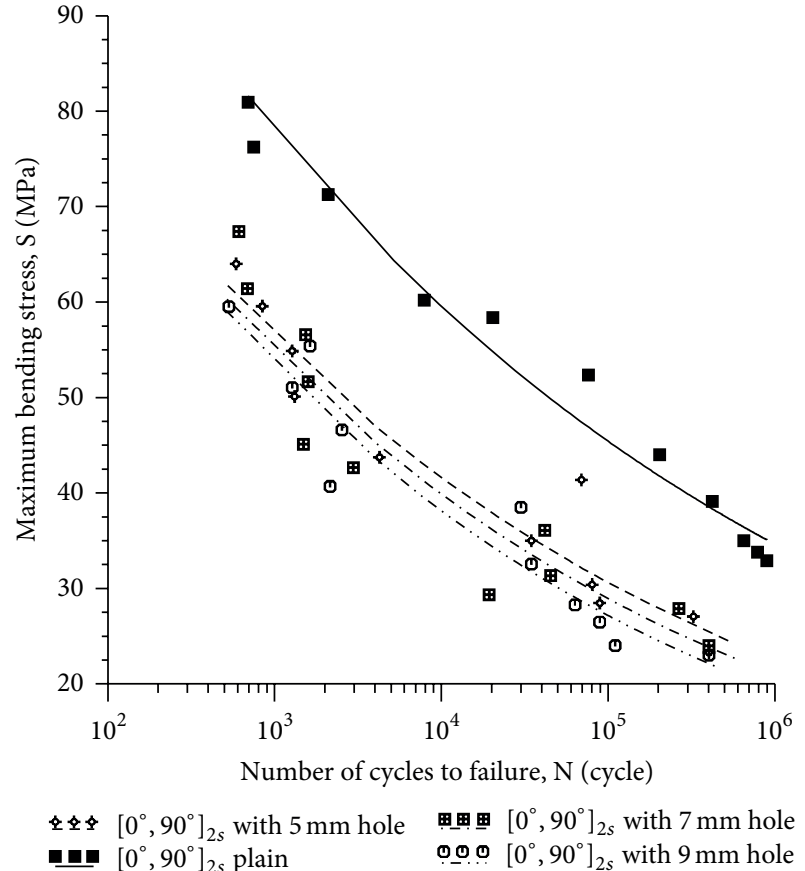

Figure 5: $S$ - $N$ curves of $\left[0^{\circ}, 90^{\circ}\right]_{2 s}$ plain specimens and notched specimens with 5,7 , and $9 \mathrm{~mm}$ diameter holes.

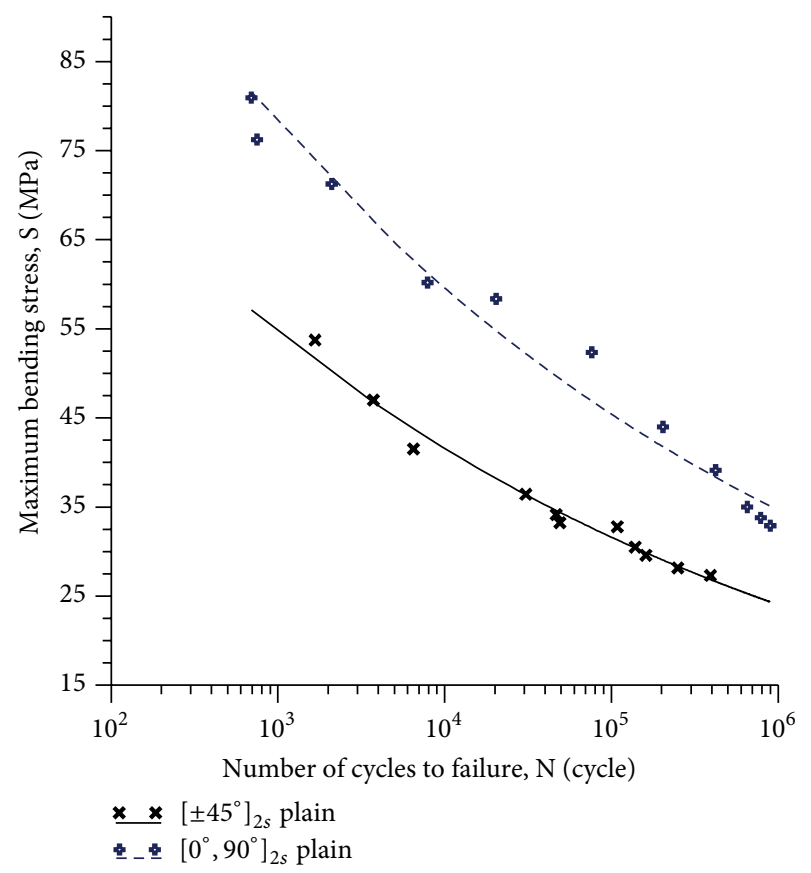

FIgURE 6: $S-N$ curves of $\left[0^{\circ}, 90^{\circ}\right]_{2 s}$ and $\left[ \pm 45^{\circ}\right]_{2 s}$ plain specimens.

$\left[0_{2} / 90_{2}\right]_{s}$ laminate having a center notch by Binienda et al. [34]. They noticed that the driving force was the interfacial shear due to load transfer from the fiber bundle cut by the hole to the fiber bundle which is uncut; see Figure 14.

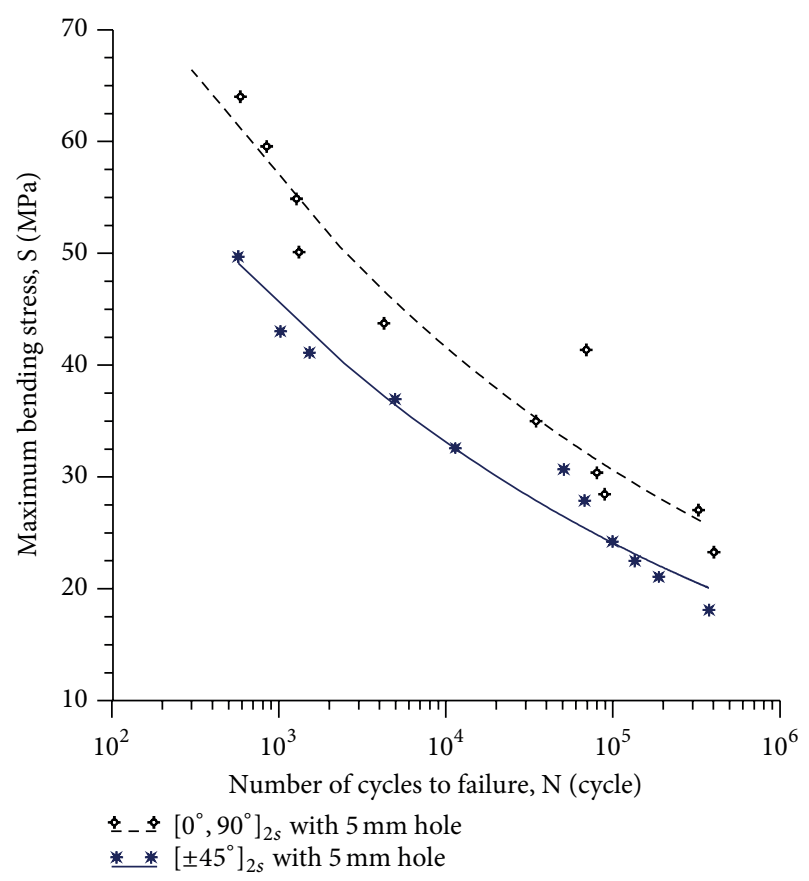

Figure 7: $S-N$ curves of $\left[0^{\circ}, 90^{\circ}\right]_{2 s}$ and $\left[ \pm 45^{\circ}\right]_{2 s}$ specimens with $5 \mathrm{~mm}$ diameter holes.

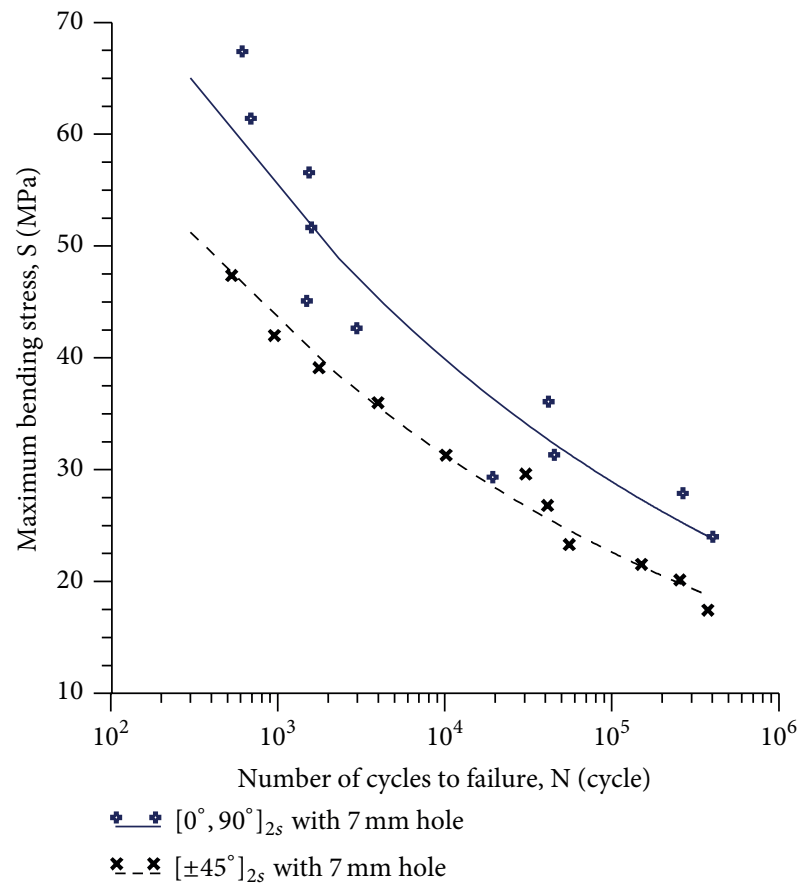

Figure 8: $S-N$ curves of $\left[0^{\circ}, 90^{\circ}\right]_{2 s}$ and $\left[ \pm 45^{\circ}\right]_{2 s}$ with $7 \mathrm{~mm}$ diameter holes.

\section{Classical Theories Validation}

All discussed failure criteria have their right hand side to be unity, and the left hand side is composed of normalized local stress components added together. The left hand side of each criterion will be called the calculated relative damage 


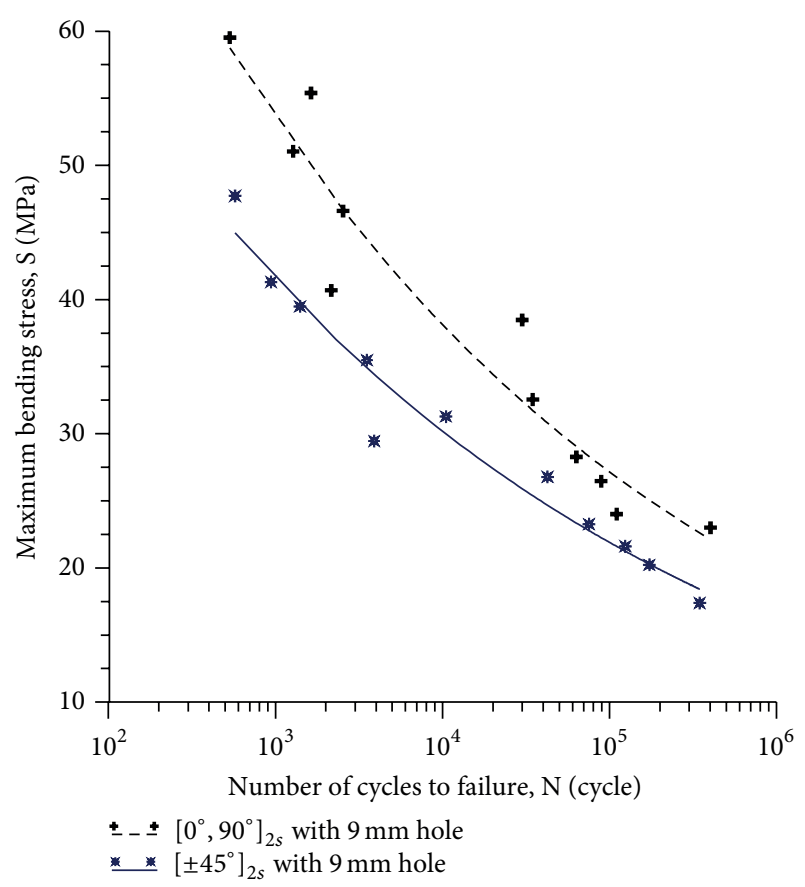

Figure 9: $S$ - $N$ curves of $\left[0^{\circ}, 90^{\circ}\right]_{2 s}$ and $\left[ \pm 45^{\circ}\right]_{2 s}$ specimens with $9 \mathrm{~mm}$ diameter hole.

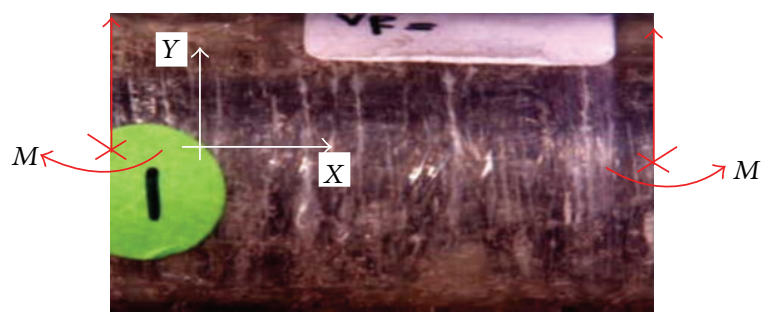

Figure 10: Failed $\left[0^{\circ}, 90^{\circ}\right]_{2 s}$ plain specimen.

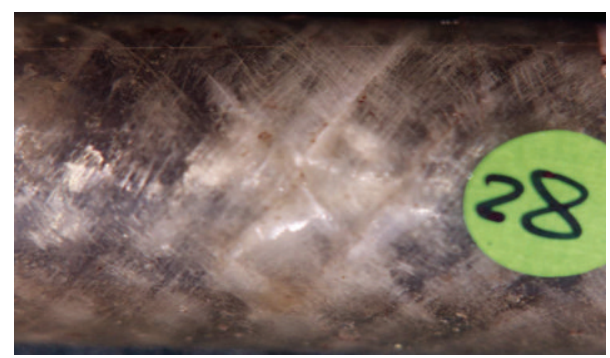

FIGURE 11: Failed $\left[ \pm 45^{\circ}\right]_{2 s}$ plain specimen.

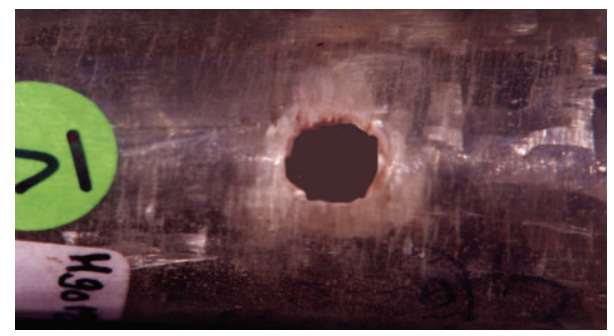

Figure 12: Failed $\left[0^{\circ}, 90^{\circ}\right]_{2 s}$ specimen with hole.

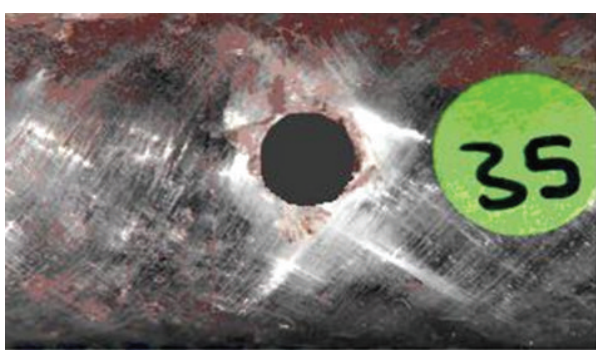

FIGURE 13: Failed $\left[ \pm 45^{\circ}\right]_{2 s}$ specimen with hole.

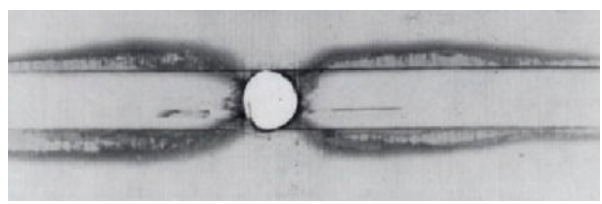

FIGURE 14: X-radiograph of matrix crack development in $\left[0_{2} / 90_{2}\right]_{s}$ graphite epoxy laminate loaded in axial tension (photo courtesy of Binienda et al. [34]).

(R.D.). The validity of the manipulated criteria depends on the propinquity of its calculated R.D. value from unity. Using the reduced forms of the failure criteria, the calculated R.D. is plotted against the cycles to failure for the two fiber orientations.

For $\left[0^{\circ}, 90^{\circ}\right]_{2 s}$ specimen, the calculated R.D. is unity regardless of the specimen life and the used failure criteria; see Figure 15. The justification is that, in $\left[0^{\circ}, 90^{\circ}\right]$ fiber orientation, the all theories of failure yielded to the same form shown in Table 2. Besides, the shear component which is blamed for the specimens' failure does not exist in the reduced classical failure criteria for $\left[0^{\circ}, 90^{\circ}\right]_{2 s}$ fiber orientation.

In the $\left[ \pm 45^{\circ}\right]$ fiber orientation, the calculated relative damage values calculated by the above criteria listed in Table 2 are different. Figure 16 shows that the calculated R.D. using the Hill criterion [35] is very small compared to unity and almost constant regardless of the notch diameter or the number of cycles. The calculated R.Ds. are exactly the same for the criteria [20-26] listed in second row of Table 2; see Figure 17. The reason is that these theories yield to the same reduced form as shown in Table 2. Figure 18 shows that the R.D. calculated from the Norris interaction theory is the largest between the calculated R.D. values discussed before. It is also noticed that this value is almost constant regardless of the number of cycles or the notch diameter. From Figure 19, it is noticed that Ashkenazi criterion is overestimating the failure where the relative damage values are greater than one regardless of the number of cycles. Besides, the relative damage varies with the notch radii. Accordingly and for simplicity, this criterion is not considered for further investigation in the following section.

4.1. Interfacial Shear Correction Factor for $\left[ \pm 45^{\circ}\right]_{2 s}$ Specimens. The simple classical phenomenological theories discussed above will be modified to account for the interfacial shear 


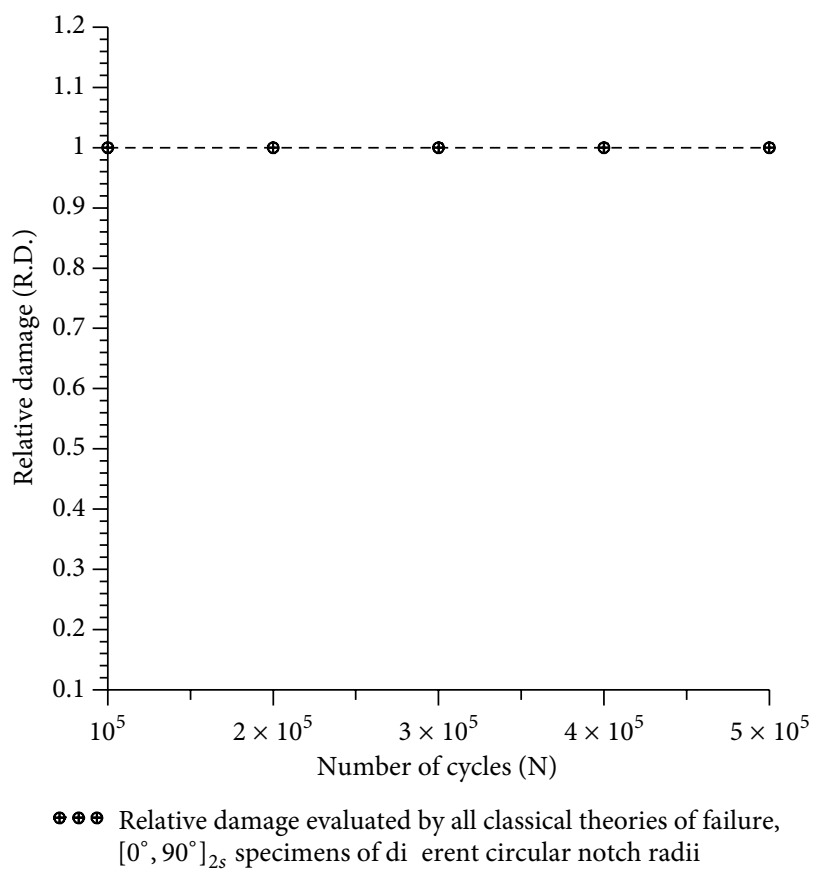

Figure 15: Relative damage evaluated by all classical theories of failure for $\left[0^{\circ}, 90^{\circ}\right]_{2 s}$ specimens.

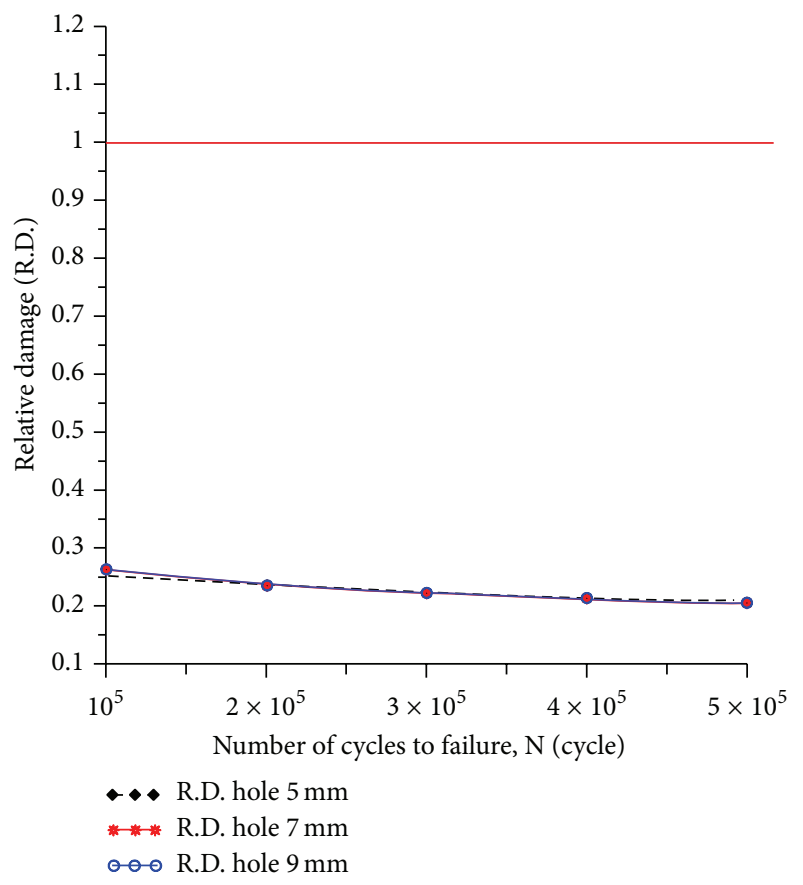

FIGURE 16: Relative damage evaluated by Hill criterion [35] for $\left[ \pm 45^{\circ}\right]_{2 s}$ specimens.

failure modes visibly shown in the failed specimens; recall Figures 10-14.

In the Hill criterion [35], it is noticed that the only surviving term is the $\left(\sigma_{6} / F_{6}\right)^{2}$, which is common in the all reduced forms of the $\left[ \pm 45^{\circ}\right]_{2 s}$ specimens. Accordingly, the calculated R.D. value from this theory is expected and

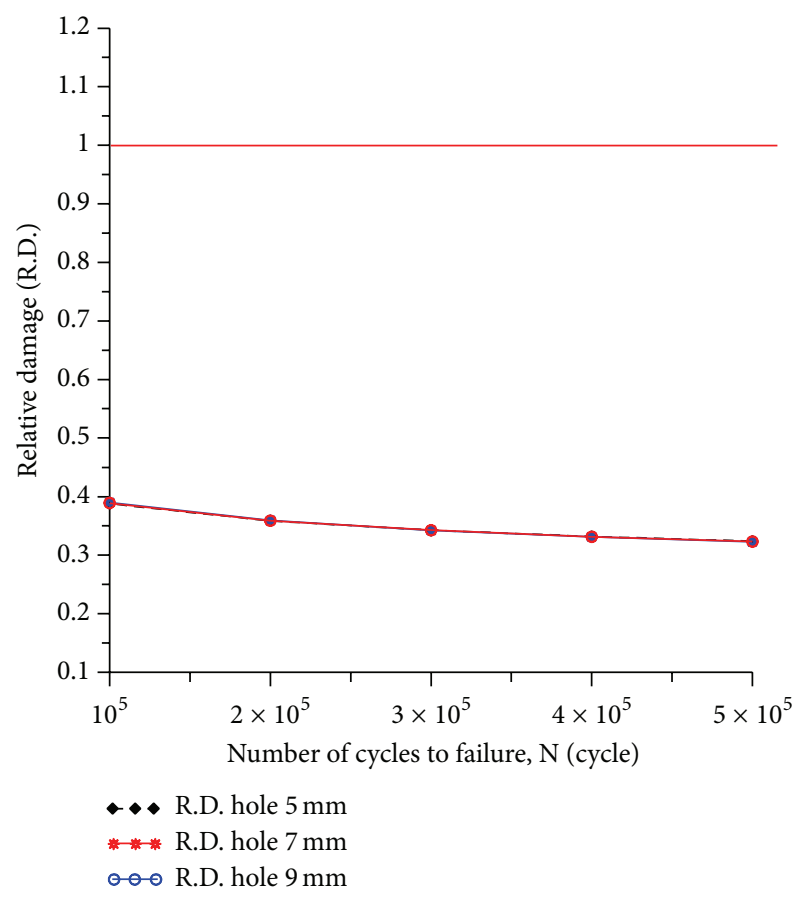

FIGURE 17: Relative damage evaluated by Tsai-Hill yield [26], Norris distortional energy [20], Hoffman [21], Tsai-Wu [22], Tsai-Hahn [23], Cowin [24], and Puppo [25] criteria for $\left[ \pm 45^{\circ}\right]_{2 s}$ specimens.

observed to be the smallest value as the local shear stress component does not include the augmentation of its value due to the overlooked interfacial shear failure mechanism. The R.D. value calculated from Norris interaction reduced criterion [36] is the greatest between the all calculated R.D. values except the refused Ashkenazi [37] as mentioned before. The justification for this is that the double value of the normalized local normal stress $\left(\sigma_{1} / F_{1}\right)^{2}$ contributes to the R.D. value beside the shear term.

Also recall that the visual inspection of Figures 11 and 13 shows a white zone extended along the fiber tangent to the notch that fortifies the existence of interfacial shear failure, although the microscopic inspection is not implemented. Accordingly, the normalized local shear stress component will be augmented by a proposed correction factor. This factor is called interfacial shear correction factor and is denoted $\mathrm{MH}_{6}$. The $\mathrm{MH}_{6}$ will be simply multiplied by the local shear stress component $\sigma_{6}$ in the above discussed theories. Thus, the corrected failure criteria could fairly be used with the thin-layered $\left[ \pm 45^{\circ}\right]_{2 s}$ WRFRC materials subjected to flexural fatigue stress. The only surviving term in the reduced criteria applied to the $\left[0^{\circ}, 90^{\circ}\right]_{2 s}$ specimens is $\left(\sigma_{1} / F_{1}\right)^{2}$; hence the $\mathrm{MH}_{6}$ factor is no longer needed for validating these theories to the thin-layered $\left[0^{\circ}, 90^{\circ}\right]_{2 s}$ WRFRC materials subjected to flexural fatigue stress.

As the R.D. value differs from theory to another, the values of the $\mathrm{MH}_{6}$ factors are expected to be different as shown in Figure 20. From Figure 20, it is noticed that the smaller the R.D. value, the greater the interfacial shear correction factor. Besides, as the shear correction factor is used to 


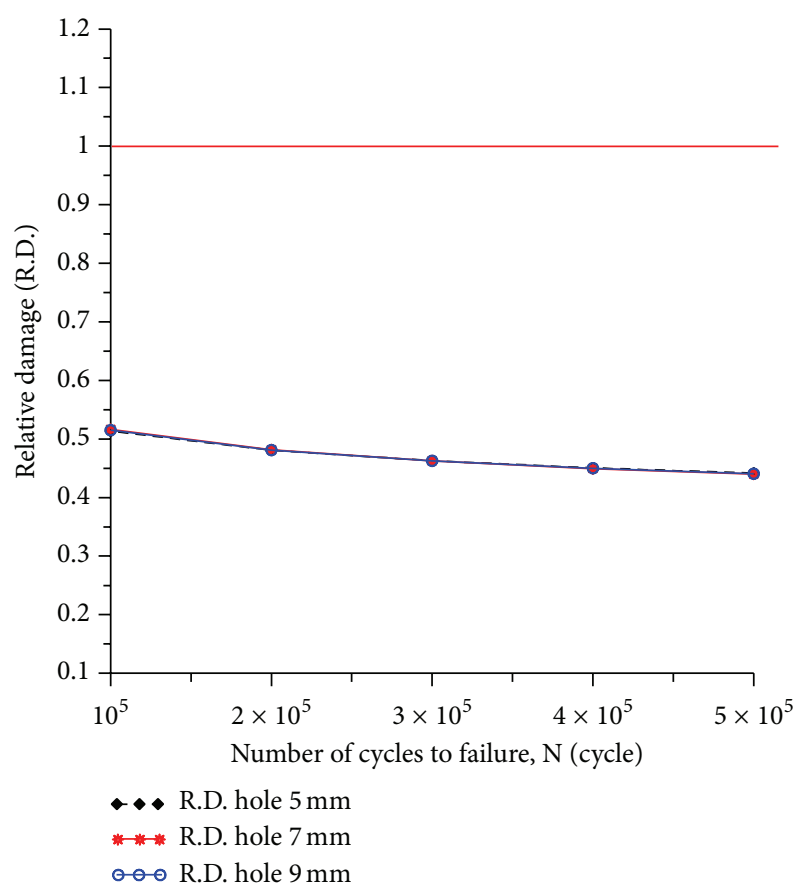

FIGURE 18: Relative damage evaluated by Norris interaction criterion $[36]$ for $\left[ \pm 45^{\circ}\right]_{2 s}$ specimens.

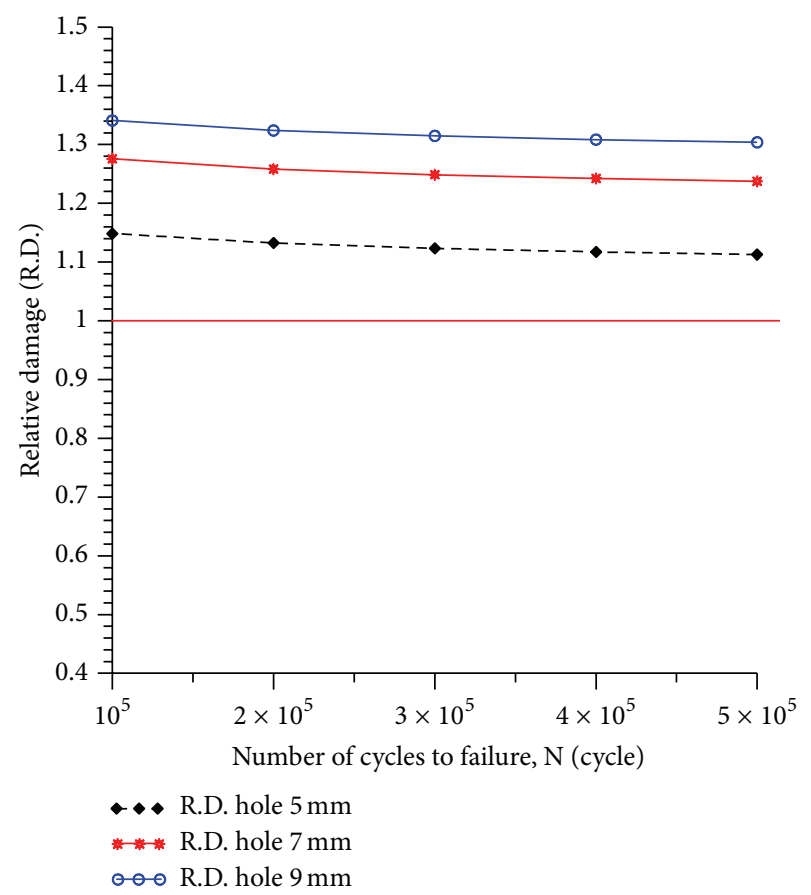

FIGURE 19: Relative damage evaluated by Ashkenazi [37] criterion for $\left[ \pm 45^{\circ}\right]_{2 s}$ specimens.

account for the overlooked interfacial shear correction failure mechanism which is microscopic in nature, thus it should be independent of the dimension of the macroscopic source of stress concentration (circular notch). This is obvious in Figure 20 as the $\mathrm{MH}_{6}$ is independent of the normalized notch radius.

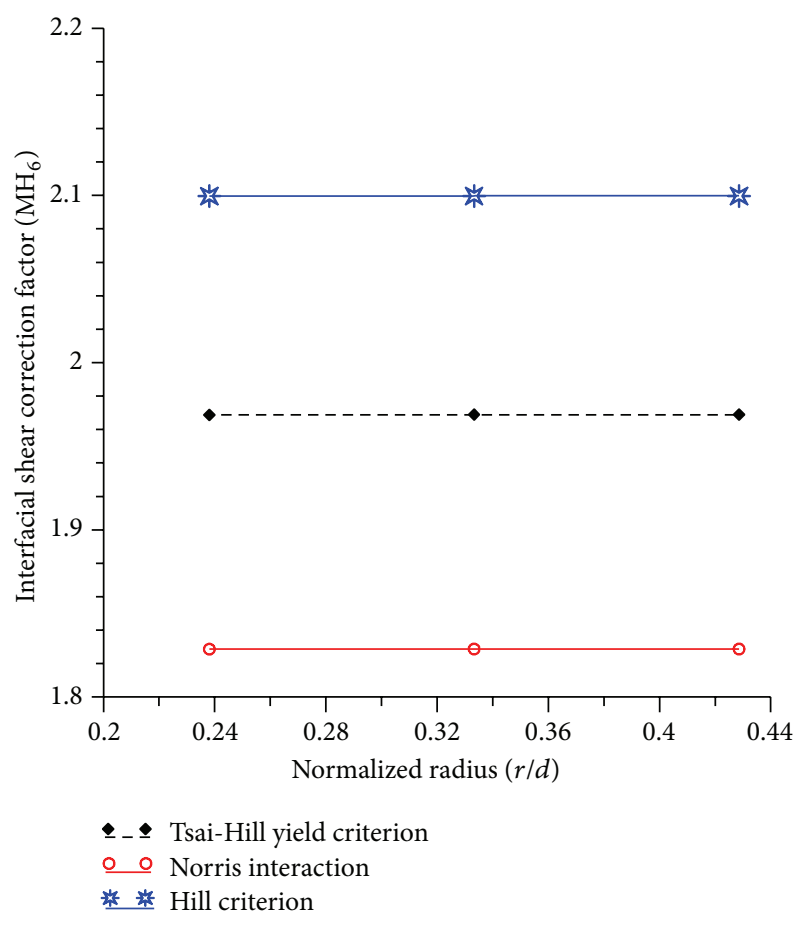

FIGURE 20: Interfacial shear correction factor used with Norrisinteraction [36], Hill criterion [35], and Tsai-hill yield criterion [26].

\section{Conclusion}

One of the microscopic failure mechanisms that the classical failure theories did not consider is the interfacial shear failure. The effect of overlooking this microscopic failure mechanism leads to poor applicability of these criteria to the wovenroving composite materials with $\left[ \pm 45^{\circ}\right]$ fiber orientation. As the local shear stress component, $\sigma_{6}$, is the driving force of the propagating interfacial debonds, the interfacial shear correction factor $\left(\mathrm{MH}_{6}\right)$ is proposed. This factor is independent of the notches' dimensions. The classical failure criteria applied to the $\left[0^{\circ}, 90^{\circ}\right]_{2 s}$ specimens are not modified to account for the interfacial shear failure. The justification is that the $\left[0^{\circ}, 90^{\circ}\right]_{2 s}$ specimen behaves like isotropic materials under the loading conditions in the current investigation and the classical failure criteria of composite materials were based on isotropic-like material assumptions. Finally, under the completely reversed bending loading, the $\left[0^{\circ}, 90^{\circ}\right]_{2 s}$ fiber oriented woven-roving composite materials are more reliable than those of $\left[ \pm 45^{\circ}\right]$ fiber orientations.

\section{Nomenclature}

$\sigma_{\max }:$ Maximum stress

$N$ : Number of cycles to failure

$\sigma_{1}$ : Local normal stress in fiber longitudinal direction

$\sigma_{2}$ : Local normal stress in fiber transverse direction

$\sigma_{6}: \quad$ Local shear stress

$\sigma_{x}$ : Global normal stress in the loading axis

$\sigma_{y}$ : Global normal stress normal to the loading axis 
$\tau_{x y}:$ Global torsion stress

$F_{1}$ : Fatigue strength in fiber longitudinal orientation

$F_{2}$ : Fatigue strength in diber transverse direction

$F_{i c}$ : Compressive fatigue strength in fiber $i$ orientation, where $i=1$ or 2

$F_{i t}: \quad$ Tensile fatigue strength in fiber $i$ orientation, where $i=1$ or 2

$M$ : Applied bending moment

$M_{m}$ : Mean bending moment

$M_{v}$ : Variable bending moment

A: Amplitude of applied bending moment

$\omega t$ : Angular displacement

$\theta: \quad$ Fiber orientation direction

$Y$ : $\quad$ Mean radius of specimen

I: $\quad$ Second polar moment of area of specimen

$k$ : $\quad$ Fatigue strength prediction factor for FRP

$R: \quad$ Stress ratio between minimum and maximum value

$r$ : Radius of the circular hole

$d$ : Mean diameter of the thin-layered specimens

$V_{f}$ : Fiber volume fraction.

\section{Conflict of Interests}

The authors declare that there is no conflict of interests regarding the publication of this paper.

\section{References}

[1] M. M. Y. B. Elshabasy, M. N. Abou El-Wafa, A. H. Hamdy, and A. A. Elmidany, "Comparison between inclusions and holes as stress kaisers in composite materials used in wind turbine components," in Proceedings of the 45th AIAA Aerospace Sciences Meeting and Exhibit, AIAA-2007-0819, Reno, Nev, USA, 2007.

[2] P. S. Chua and M. R. Piggott, "The glass fiber-polymer interface: II work of fracture and shear stresses," Composites Science and Technology, vol. 22, no. 2, pp. 107-119, 1985.

[3] P. S. Chua and M. R. Piggott, “The glass fibre-polymer interface: III pressure and coefficient of friction," Composites Science and Technology, vol. 22, no. 3, pp. 185-196, 1985.

[4] P. S. Chua and M. R. Riggott, "The glass fibre-polymer interface: IV controlled shrinkage polymers," Composites Science and Technology, vol. 22, no. 4, pp. 245-258, 1985.

[5] R. Swan, K. L. Reifnider, K. Jayaraman, and M. El-Zein, "Interface/interphase concepts in composite materials systems," Journal of Thermoplastic Composite Materials, vol. 3, no. 1, pp. 13-23, 1990.

[6] E. J. Chen and J. C. Young, "The micro-debonding test systems a method of quantifying adhesion in real composites," Composites Science and Technology, vol. 42, no. 1-3, pp. 189-206, 1991.

[7] L. J. Broutman, "Measurement of the fiber-polymer matrix interfacial strength," in Interfaces in Composites, vol. 452 of ASTM Specical Technical Publication, pp. 27-41, ASTM International, 1969.

[8] A. Kelly and W. R. Tyson, "Tensile properties of fibre-reinforced metals: copper/tungsten and copper/molybdenum," Journal of the Mechanics and Physics of Solids, vol. 13, no. 6, pp. 329-350, 1965.

[9] D. H. Grande, Microdebonding Test for Measuring Shear Strength of the Fiber/Matrix Interface in Composite Materials [M.S. thesis], Department of Materials Science and Engineering, Massachusetts Institute of Technology, Boston, Mass, USA, 1983.

[10] K. Jayaraman and K. L. Reifsnider, "The interphase in unidirectional fiber-reinforced epoxies: effect on residual thermal stresses," Composites Science and Technology, vol. 47, no. 2, pp. 119-129, 1993.

[11] J. K. Jim and Y. W. Mai, Engineered Interfaces in Fiber Reinforced Composites, Elsevier, London, UK, 1st edition, 1998.

[12] A. Dasgupta and J. S. Sirkis, "The importance of coatings to structurally embedded optical fiber sensors in smart structures," AIAA journal, vol. 30, no. 5, pp. 1337-1343, 1992.

[13] G. P. Carman and S. W. Case, "Minimizing stress concentrations in material systems with appropriate fiber coatings," in Proceedings of the 7th Technical Conference, American Society for Composites, pp. 889-898, Technomic, 1992.

[14] G. P. Carman, R. C. Averill, K. L. Reifsnider, and J. N. Reddy, "Optimization of fiber coatings to minimize stress concentrations in composite materials," Journal of Composite Materials, vol. 27, no. 6, pp. 589-612, 1993.

[15] M. S. Madhukar and L. T. Drazal, "Fiber-matrix adhesion and its effect on composite mechanical properties. I. Inplane and interlaminar shear behavior of graphite/epoxy composites," Journal of Composite Materials, vol. 25, no. 8, pp. 932-957, 1991.

[16] M. S. Madhukar and L. T. Drazal, "Fiber-matrix adhesion and its effect on composite mechanical properties. II. Longitudinal $\left(0^{\circ}\right)$ and transverse $\left(90^{\circ}\right)$ tensile and flexure behavior of graphite/epoxy composites," Journal of Composite Materials, vol. 25, no. 8, pp. 958-991, 1991.

[17] M. S. Madhukar and L. T. Drazal, "Fiber-matrix adhesion and its effect on composite mechanical properties. III. Longitudinal $\left(0^{\circ}\right)$ compressive properties of graphite/epoxy composites," Journal of Composite Materials, vol. 26, no. 3, pp. 310-333, 1992.

[18] M. S. Madhukar and L. T. Drazal, "Fiber-matrix adhesion and its effect on composite mechanical properties: IV. Mode I and mode II fracture toughness of graphite/epoxy composites," Journal of Composite Materials, vol. 26, no. 7, pp. 936-968, 1992.

[19] K. E. Remple and T. Niu, "Graphite/epoxy [ \pm 45$]$ s tubes, their static axial \& shear properties and their fatigue behavior under completely reversed loading," Journal of Composite Materials, vol. 16, no. 3, pp. 172-187, 1982.

[20] C. B. Norris, "Strength of orthotropic materials subjected to combined stress US forest products," Laboratory Report 1816, 1962.

[21] N. O. Hoffman, "The brittle strength of orthotropic materials," Journal of Composite Materials, vol. 1, no. 2, pp. 200-206, 1967.

[22] S. W. Tsai and E. M. Wu, "A general theory of strength for anisotropic materials," Journal of Composite Materials, vol. 5, pp. 58-80, 1971.

[23] S. W. Tsai and H. T. Hahn, Introduction to Composite Materials, Technomic, Westport, Conn, USA, 1980.

[24] S. C. Cowin, "On the strength anisotropy of bone and wood," Journal of Applied Mechanics, vol. 46, no. 4, pp. 832-838, 1979.

[25] A. H. Puppo and H. A. Evensen, "Strength of anisotropic materials under combined stresses," AIAA Journal, vol. 10, no. 4, pp. 468-474, 1972. 
[26] V. D. Azzi and S. W. Tsai, "Anisotropic strength of composites," Experimental Mechanics, vol. 5, no. 9, pp. 283-288, 1965.

[27] M. N. Abouelwafa, A. H. Hamdy, and E. A. Showaib, "A new testing machine for fatigue under combined bending and torsion acting out-of-phase," Alexandria Engineering Journal, vol. 28, no. 4, pp. 113-130, 1989.

[28] A. I. Sharara, Effect of Stress Ratio on Fatigue Characteristics of Woven-Roving Glass Reinforced Polyester [M.S. thesis], Faculty of Engineering, Alexandria University, Alexandria, Egypt, 1997.

[29] M. M. Y. B. Elshabasy, The Inclusion Effect on the Fatigue Strength of Woven Roving GRP Composite Materials [M.S. thesis], Faculty of Engineering, Alexandria University, Alexandria, Egypt, 2001.

[30] A. J. Elkhateeb, Delamination Growth of Glass Fiber Reinforced Composite under Cyclic Torsional Moments [Ph.D. dissertation], Faculty of Engineering, Alexandria University, Alexandria, Egypt, 2001.

[31] A. A. El-Midany, Fatigue of Woven-Roving Glass Fiber Reinforced Polyester Under Combined Bending and Torsion [Ph.D. dissertation], Faculty of Engineering, Alexandria University, Alexandria, Egypt, 1995.

[32] C. C. Chamis, Mechanics of Load Transfer at the Fiber/ Matrix Interface NASA TN D-6588, 1972.

[33] "Tentative specification for woven roving glass fabric for polyester glass laminates ASTM designation,” Tech. Rep. D215063T, 1963.

[34] W. Binienda, A. S. D. Wang, Y. Zhong, and E. S. Reddy, "A criterion for mixed-mode matrix cracking in graphite-epoxy," in Composites Composite Materials: Testing and Design, S. P. Garbo, Ed., vol. 9 of Special Technical Publication, pp. 287-300, American Society for Testing and Materials, Philadelphia, Pa, USA, 1990.

[35] R. A. Hill, "Theory of the yielding and plastic flow of anisotropic metals," Proceedings of the Royal Society of London. Series A, Mathematical and Physical Sciences, vol. 193, pp. 281-297, 1948.

[36] C. B. Norris and P. F. McKinnon, "Supplement to compression, tension, and shear tests on yellow poplar plywood panels of sizes that do not buckle with tests made at various angles to the face grain (shear tests) US forest products," Laboratory Report 1328, 1956.

[37] E. K. Ashkenazi, "On the problem of strength for anisotropic materials," Technical Physics, vol. 4, no. 3, pp. 333-338, 1959. 

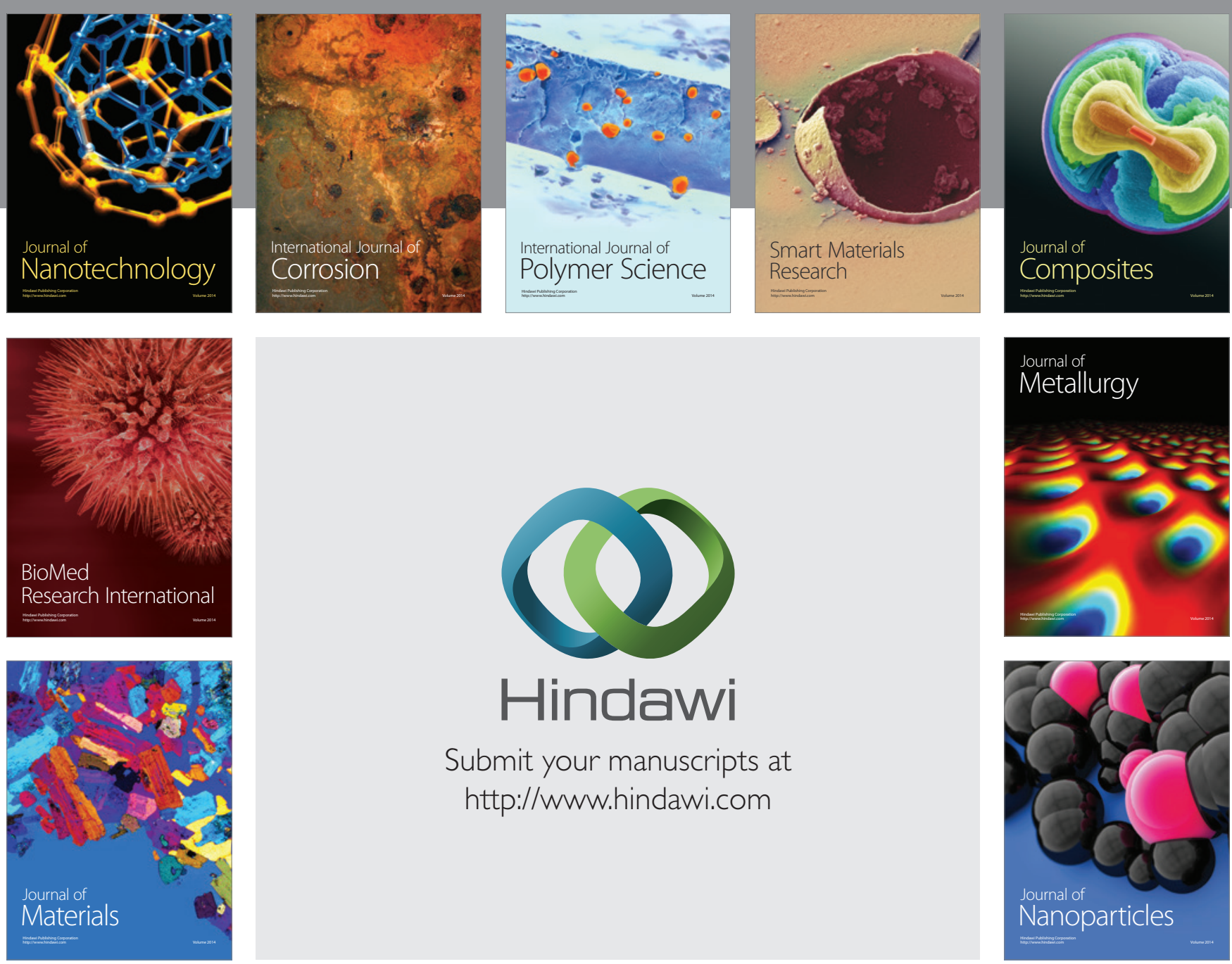

Submit your manuscripts at http://www.hindawi.com
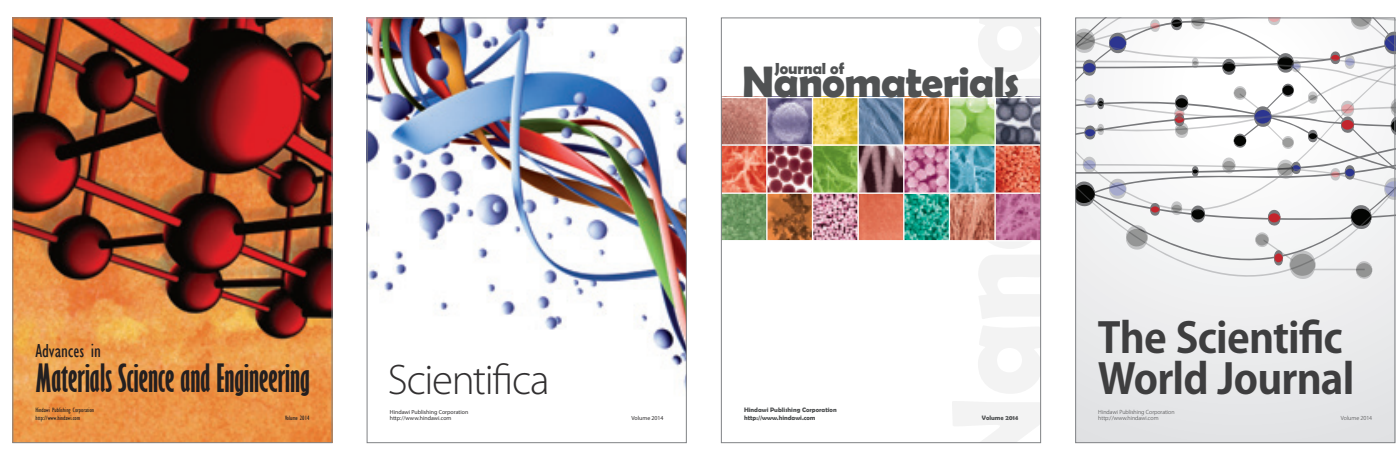

\section{The Scientific World Journal}
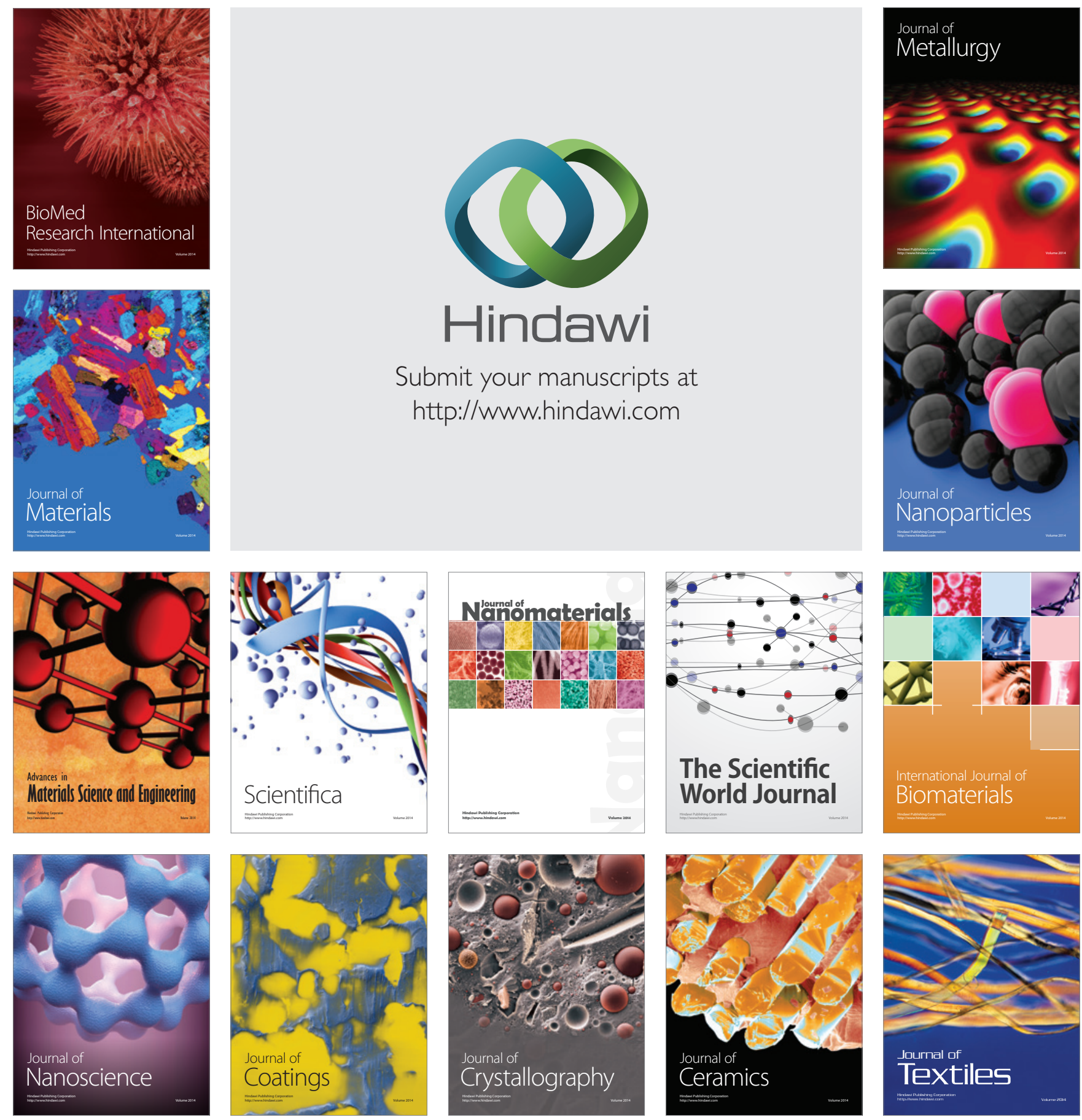